OPEN Metal Halide Solid-State Surface

SUBJECT AREAS:

QUANTUM DOTS

SOLAR CELLS

Received

13 December 2014

Accepted

16 March 2015

Published

24 April 2015

Correspondence and requests for materials should be addressed to

J.M.L. (joey.luther@ nrel.gov)

\title{
Treatment for High Efficiency PbS and PbSe QD Solar Cells
}

\author{
Ryan W. Crisp" ,2, Daniel M. Kroupa 1,3, Ashley R. Marshall 1,3, Elisa M. Miller ${ }^{1}$, Jianbing Zhang ${ }^{1,4}$, \\ Matthew C. Beard' \& Joseph M. Luther'
}

\begin{abstract}
${ }^{1}$ National Renewable Energy Laboratory, Golden, CO 80401 USA, ${ }^{2}$ Department of Physics, Colorado School of Mines, Golden, CO 80401 USA, ${ }^{3}$ Department of Chemistry and Biochemistry, University of Colorado, Boulder, CO 80309 USA, ${ }^{4}$ School of Optical and Electronic Information, Huazhong University of Science and Technology, Hubei 430074, China.
\end{abstract}

We developed a layer-by-layer method of preparing $\mathrm{PbE}(\mathrm{E}=\mathrm{S}$ or $\mathrm{Se})$ quantum dot $(\mathrm{QD})$ solar cells using metal halide $\left(\mathrm{PbI}_{2}, \mathrm{PbCl}_{2}, \mathrm{CdI}_{2}\right.$, or $\left.\mathrm{CdCl}_{2}\right)$ salts dissolved in dimethylformamide to displace oleate surface ligands and form conductive QD solids. The resulting QD solids have a significant reduction in the carbon content compared to films treated with thiols and organic halides. We find that the $\mathrm{PbI}_{2}$ treatment is the most successful in removing alkyl surface ligands and also replaces most surface bound $\mathrm{Cl}^{-}$with $\mathrm{I}^{-}$. The treatment protocol results in $\mathrm{PbS}$ QD films exhibiting a deeper work function and band positions than other ligand exchanges reported previously. The method developed here produces solar cells that perform well even at film thicknesses approaching a micron, indicating improved carrier transport in the QD films. We demonstrate $\mathrm{QD}$ solar cells based on $\mathrm{PbI}_{2}$ with power conversion efficiencies above $7 \%$.

S olution-processed photovoltaics (PV) represent a promising route forward in reducing the cost of solar energy production. Quantum dot (QD) solids are one such solution-processed system currently being researched. In addition to being solution processable, QD solar cells (QDSCs) have a higher limiting single junction power conversion efficiency than is possible using conventional bulk or thin film semiconductors due to enhanced multiple exciton generation (MEG) in the QDs ${ }^{1,2}$. Recent improvements in QDSC performance and processing ease have resulted from modification of the device architecture, processing of the QD-layers under ambient conditions, improved QD synthetic procedures and surface treatments improving QD passivation ${ }^{3-6}$. A critical component of the progress listed above is the incorporation of halides into the QD matrix ${ }^{6,7}$. Specifically, $\mathrm{Cl}^{-}$anions were shown to improve stability while passivating trap states that lower the minority-carrier lifetime $^{3,4,8}$. Incorporation of these halide anions has been achieved by using chloride precursors in the QD synthesis ${ }^{3}$, using post-synthesis solution treatments ${ }^{9-11}$, and, recently, employing ammonium halide salts as the only ligand treatment ${ }^{6,12}$. However, when using the previously reported halide passivation schemes, organic molecules that are instrumental in delivering the halide anion (e.g. tetrabutylammonium iodide (TBAI), 3-chloropropane-1-thiol, methylammonium iodide (MAI), etc.), leave behind cationic organic residue that could potentially limit device performance. In contrast, here, we demonstrate a procedure that removes nearly all of the organic moieties from the QD solid during device fabrication. The groups of Wang, Talapin, and Kovalenko have previously reported solution-phase ligand exchanges using halide ligands but have not applied them to solar cells $\mathrm{s}^{13-15}$. Our procedure is based upon a layer-by-layer approach demonstrated previously but uses metal halides dissolved in dimethlyformamide (DMF) (rather than thiols in acetonitrile or alcohols) to build-up thick, all-inorganic films by either dip coating or spin coating with $\mathrm{PbS}$ or PbSe QDs.

\section{Results}

The QD synthesis used in this study follows previous reports where $\mathrm{PbE}(\mathrm{E}=\mathrm{S}, \mathrm{Se}) \mathrm{QDs}$ are made by cation exchange of CdE QDs with $\mathrm{PbCl}_{2} /$ oleylamine $e^{4}$. Of the numerous metal halide materials available, we focus on four metal halides solvated in DMF: $\mathrm{PbCl}_{2}, \mathrm{PbI}_{2}, \mathrm{CdCl}_{2}$, and $\mathrm{CdI}_{2}$. The chosen metal halides introduce ions $\left(\mathrm{Cl}^{-}\right.$or $\left.\mathrm{I}^{-}\right)$ that have demonstrated passivation of QD trap states. Metal halides have not previously been used as the sole ligand treatment for QDSCs but rather as a pre- or post-treatment in conjunction with short-chained alkyl thiol 

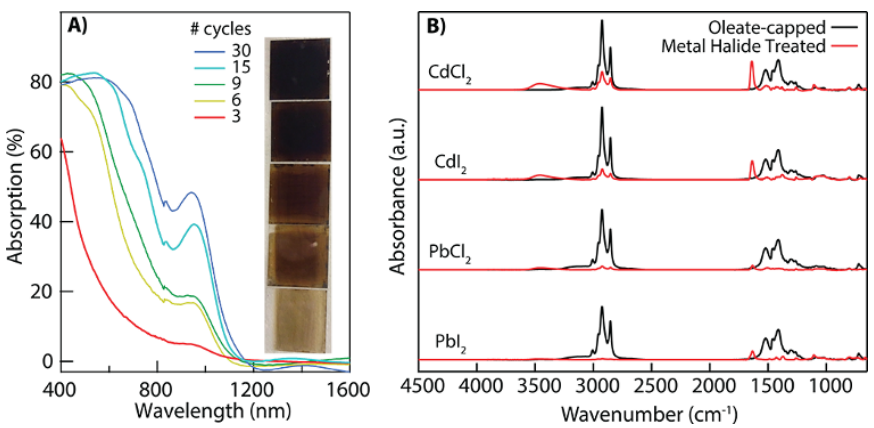

Figure $1 \mid$ A) Absorption spectra calculated by measuring the transmission and reflection spectra of dip coated PbS QD films on glass as a function of the number of dip cycles using $\mathrm{PbI}_{2}$. Inset: photograph of $\mathrm{PbS}$ QD films with variable thickness controlled by the number of dip cycles given in the legend. B) Fourier-Transform Infrared (FTIR) spectra of $1.3 \mathrm{eV}$ bandgap PbS QDs dropcast from hexane (black traces) and then soaked for 2 hours in $10 \mathrm{mM}$ metal halide in $\mathrm{N}, \mathrm{N}$-dimethylformamide (DMF) (red traces). The peak at $1640 \mathrm{~cm}^{-1}$ is attributed to residual DMF that can be removed with heating and/or placing the film under vacuum.

ligands. Previous reports indicate soaking QD solids in neat DMF displaces the native oleate ligands derived from oleic acid (OA) and leads to oriented attachment along the (100) facets of the PbE QDs ${ }^{16}$. Here, we find that the metal-halide:DMF treatment removes $\mathrm{Pb}$-oleate from the QDs while incorporating the metal halide into the film as is discussed below.

Dip coating QDs allows for a controlled thickness of a compact film with appropriate surface coverage ${ }^{17}$. In Fig. 1A, we show the increase in absorption of $\mathrm{PbS}$ QD films with increasing number of deposition cycles while preserving the first exciton feature originating from the individual QD size. In Fig. 1B, we show baselinecorrected Fourier-Transform Infrared (FTIR) spectra of dropcast films capped with the native oleate ligand (black lines) and the corresponding spectra after ligand treatment with various metal halide salts in DMF (red lines). Based on the ratios of the largest absorbance feature at $2925 \mathrm{~cm}^{-1}$ (corresponding to the $v_{a}\left(-\mathrm{CH}_{2}\right)$ mode), the iodide salts remove more $\mathrm{Pb}$-oleate than their respective chloride salts (i.e. $\mathrm{CdI}_{2}$ removes more than $\mathrm{CdCl}_{2}$ ), and the lead salts remove more than the cadmium salts (i.e $\mathrm{PbI}_{2}$ is more effective than $\mathrm{CdI}_{2}$ ). This trend is deduced using a ratio of the absorbance at $2925 \mathrm{~cm}^{-1}$ i.e. [post-soak]/[pre-metal halide soak]; $26 \%$ oleate remains after treatment with $\mathrm{CdCl}_{2}, 14 \%$ after $\mathrm{CdI}_{2}$ treatment, $5.1 \%$ after $\mathrm{PbCl}_{2}$ treatment, and $1.4 \%$ after $\mathrm{PbI}_{2}$ treatment. However, some of the residual organics from DMF are still present after rinsing, as indicated by the peak near $1640 \mathrm{~cm}^{-1}$. The generality of the concept is shown by using each of the compounds in Fig. 1B, but focusing on $\mathrm{PbI}_{2}$ in DMF as a treatment to prepare QD solar cells since it is most effective at removing the oleate.

To further detail the composition and properties of the QD films treated with $\mathrm{PbI}_{2}\left(\mathrm{PbS}_{\mathrm{PbI} 2}\right)$, we examined the atomic concentrations and energy levels using x-ray photoelectron spectroscopy (XPS) and compare to that of other ligand-exchanged QD films. We fabricate films using iodine-containing ligands: $\mathrm{TBAI}$ and $\mathrm{PbI}_{2}$, as well as the

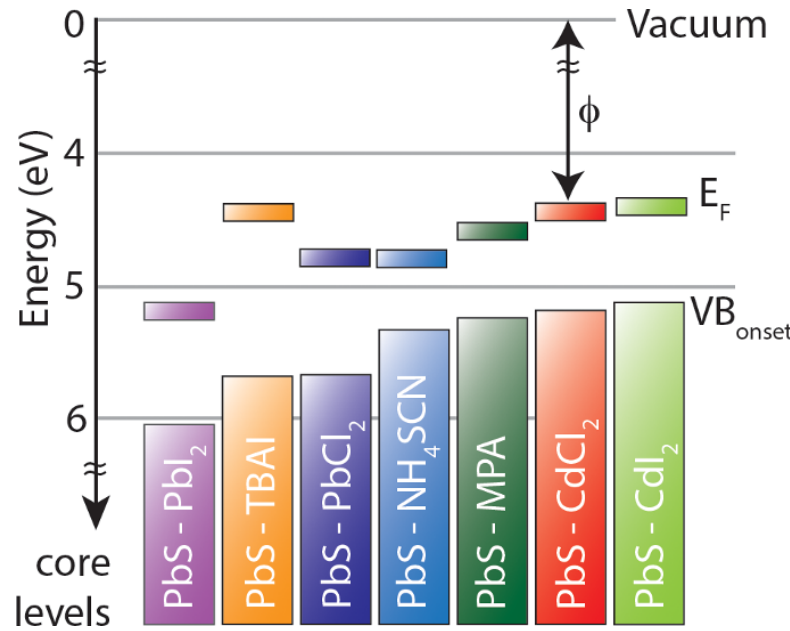

Figure 2 Summary of photoelectron spectroscopy results of $1.3 \mathrm{eV}$ bandgap PbS QDs with various surface treatments. The $\mathrm{E}_{\mathrm{F}}-\mathrm{E}_{\mathrm{VB}}$ onset and $\varphi$ of $\mathrm{PbS}$ QDs changes with $\mathrm{PbI}_{2}, \mathrm{TBAI}, \mathrm{PbCl}_{2}, \mathrm{NH}_{4} \mathrm{SCN}, \mathrm{MPA}, \mathrm{CdCl}_{2}$, and $\mathrm{CdI}_{2}$ surface treatments/ligand exchange.

sulfur-containing ligands: MPA and $\mathrm{NH}_{4} \mathrm{SCN}$. Both $\mathrm{NH}_{4} \mathrm{SCN}$ and MPA have carbon signatures greater than 20\%. Comparing QD films treated with TBAI to those treated with $\mathrm{PbI}_{2}$ in Table 1 , we find that the percentage of carbon present in the film is greatly reduced (from $26.7 \%$ to $2.5 \%$ ) when using the $\mathrm{PbI}_{2}$ treatment. Interestingly, the MPA and $\mathrm{NH}_{4} \mathrm{SCN}$ do not displace the $\mathrm{Cl}$ present in the QDs $\left(\mathrm{Cl}\right.$ added during the ion exchange reaction via $\mathrm{PbCl}_{2} /$ oleylamine ${ }^{4}$ ), whereas after treating QD films with TBAI or $\mathrm{PbI}_{2}, \mathrm{Cl}$ is not detected by XPS. This demonstrates the strong bonding character of iodine to the surface of lead chalcogenide quantum dots and may be responsible for the lessened sensitivity to oxygen in $\mathrm{PbS}$ and $\mathrm{PbSe}$ devices found here and previously ${ }^{6}$.

Researchers have demonstrated a link between the stoichiometry in ionic QDs and majority carrier type in QD films ${ }^{18,19}$. For instance, the $\mathrm{Pb}$ :E ratio decreased with the addition of chalcogens from ligands like MPA or $\mathrm{NH}_{4} \mathrm{SCN}$ resulting in p-type QD films ${ }^{18-20}$. Changes in the stoichiometry would therefore alter the Fermi level position within the bandgap. The XPS spectra can be used to determine the work function $(\varphi=$ difference between Fermi energy and vacuum level) and the onset of emitted electrons from VB states relative to the Fermi energy $\left(\mathrm{E}_{\mathrm{F}}-\mathrm{E}_{\mathrm{VB}}\right.$ onset $)$. Here we find that treating the QDs with MPA or $\mathrm{NH}_{4} \mathrm{SCN}$ decreases the $\mathrm{Pb}: \mathrm{S}$ ratio compared to the $\mathrm{I}^{-}$ treated films and the separation between the onset of the valence band (VB) states and the Fermi level is also smaller, consistent with previous reports ${ }^{21}$. In addition, the I- treatments lead to a deeper VB (i.e. larger energy difference between vacuum and the VB onset) than the sulfur-containing ligand treatments as shown in Fig. 2. With total cation:anion ratio equal to unity, the lower $\mathrm{Pb}: \mathrm{S}$ ratios for the MPA and $\mathrm{NH}_{4} \mathrm{SCN}$ treatments compared to the $\mathrm{I}^{-}$ligand treatment support the conclusion that the MPA and $\mathrm{NH}_{4} \mathrm{SCN}$ treatments lead to more $p$-type films than the $\mathrm{I}^{-}$ligand treatments ${ }^{22}$.

The XPS results of the VB onset and $\varphi$ show that the ligand can dictate the Fermi level position within the bandgap and can control

Table 1 | Relative atomic percentage of elements in ligand-exchanged QD films determined by XPS

\begin{tabular}{|c|c|c|c|c|c|c|c|c|c|c|c|c|}
\hline Treatment & C & $\mathrm{N}$ & I & $\mathrm{Cl}$ & $\mathrm{Pb}$ & $S$ & $\mathrm{O}$ & $\mathrm{Cd}$ & $\mathrm{Pb}: \mathrm{S}$ & $\mathrm{Pb}: \mathrm{I}$ & $\mathrm{Pb}: \mathrm{Cl}$ & $(\mathrm{Pb}+\mathrm{Cd}):(\mathrm{S}+\mathrm{I}+\mathrm{Cl})$ \\
\hline $\mathrm{Pbl}_{2}$ & 2.5 & $*$ & 26.9 & $*$ & 45.7 & 19.3 & 5.3 & 0.3 & 2.1 & 2.1 & & 1.0 \\
\hline TBAI & 26.7 & 1.3 & 19.2 & $*$ & 34.3 & 16.4 & 1.7 & 0.4 & 2.1 & 1.8 & & 1.0 \\
\hline MPA & 27.3 & * & * & 7.0 & 28.4 & 19.7 & 16.6 & 1.0 & 1.4 & & 4.1 & 1.1 \\
\hline
\end{tabular}

*values below detection limit 
A)

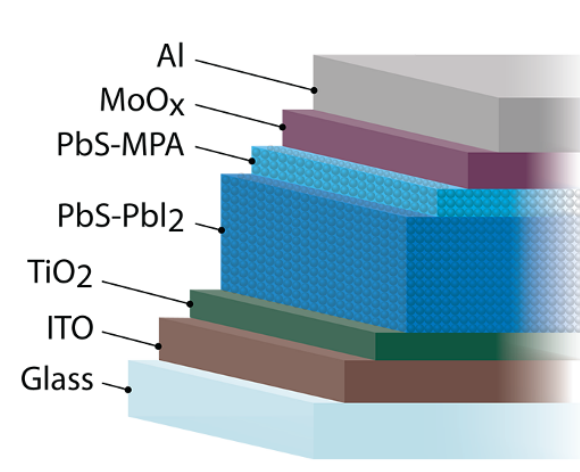

C)

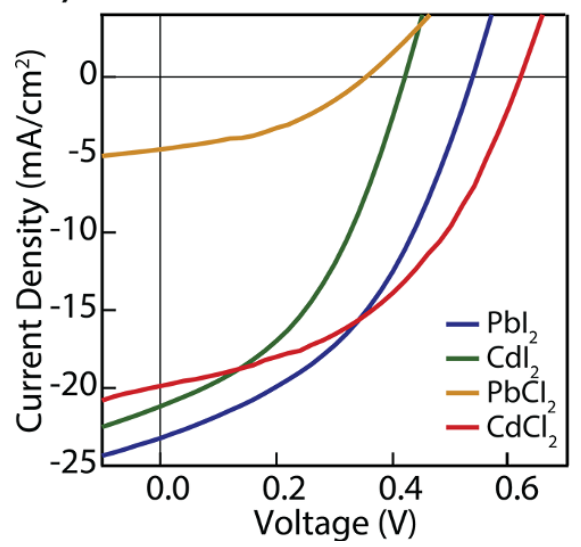

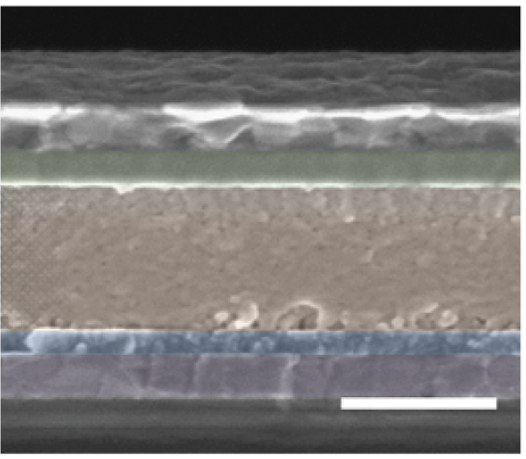

B)

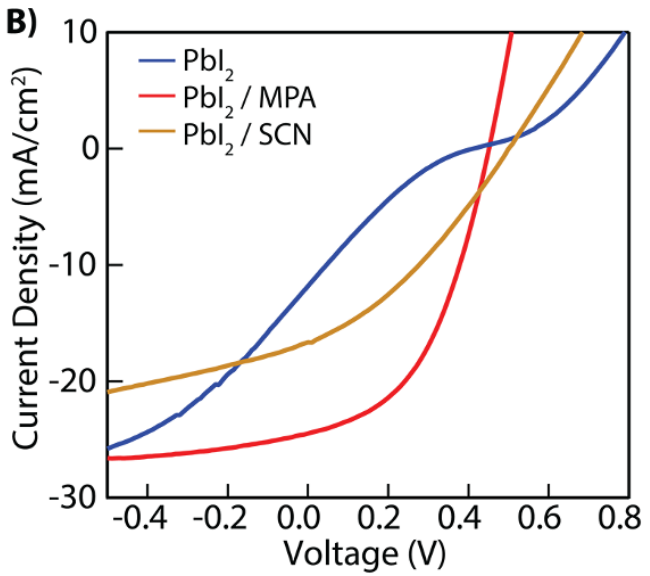

D)

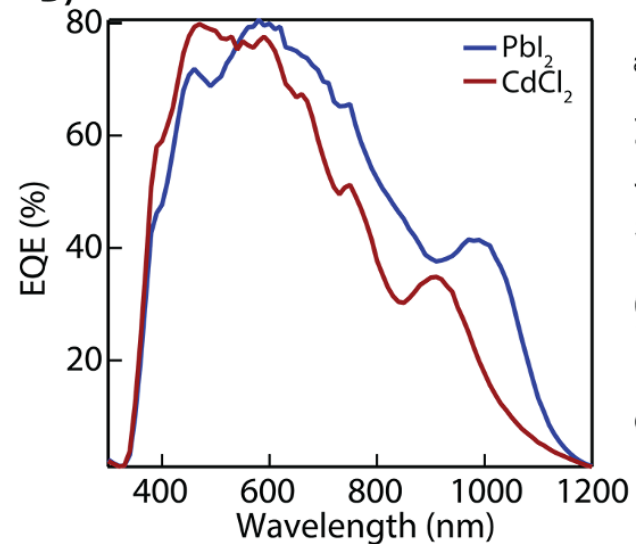

E)

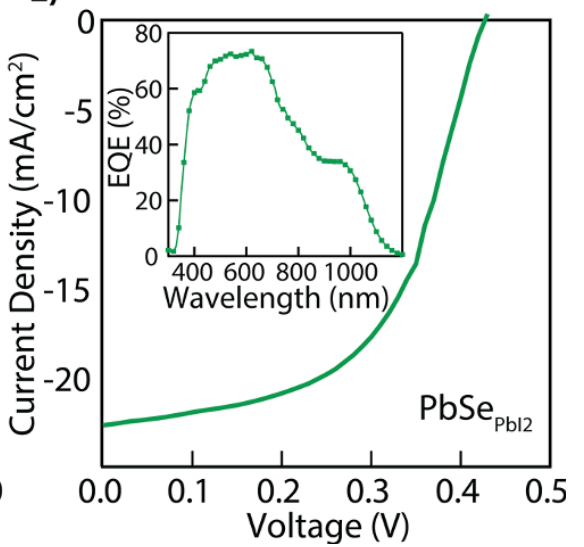

Figure $3 \mid$ A) Schematic representation of the device structure superimposed on a false-color scanning electron microscope image for a completed $\mathrm{PbS}_{\mathrm{PbI}} / \mathrm{PbS}_{\mathrm{MPA}}$ device. Scale bar is $500 \mathrm{~nm}$. B) Current-voltage characteristics using only a $\mathrm{PbI}_{2}$ treatment shows low FF (blue trace) but using a secondary layer treated with MPA (red trace) and with the inorganic SCN- ligand (gold trace) aids in band alignment yielding improved FF and PCE. C) Current-voltage characteristics of devices incorporating the four metal halides discussed above are shown. Using $\mathrm{CdCl}_{2}$ as opposed to $\mathrm{PbI}_{2}$ improves the $\mathrm{V}_{\mathrm{OC}}$ to over $615 \mathrm{mV}$. D) External quantum efficiency (EQE) curves for PbS QDSCs with $\mathrm{PbI}_{2}$ and $\mathrm{CdCl}_{2}$ ligand treatments (PbS shown in panel A). E) Current-voltage characteristics of air-fabricated PbSe $\mathrm{PbI}_{2}$ QDSC. The inset shows the external quantum efficiency for the device.

the overall band positions relative to vacuum ${ }^{21,23,24}$. Our results with the TBAI, MPA, and $\mathrm{NH}_{4} \mathrm{SCN}$ ligand treatments agree with those of Brown et al. ${ }^{21}$, and we find (Fig. 2) that the $\mathrm{PbI}_{2}$ ligand exchanged $\mathrm{PbS}$ QD film has the lowest lying VB onset and $\varphi$ of all of the ligands studied here and in previous work with $\mathrm{PbS} \mathrm{QD}$ films. Furthermore, treating the $\mathrm{PbS} \mathrm{QDs}$ with $\mathrm{CdCl}_{2}$ or $\mathrm{CdI}_{2}$ yields a shallower valence band onset. Control over both the band positions and majority carrier type within QD solids enables deliberate engineering of the energetics within a device.

We then fabricated PbE QDSCs with the structure shown in Fig. 3A. The processing details and characteristics of devices made for this study are summarized in Table 2 . The devices are fabricated in air using a layer-by-layer coating process. Both dip coating and spin coating yield nominally the same results with details given in Table 2 and the Methods section. Both of these deposition protocols allow for conformal films with well-controlled thickness. As mentioned above, a unique feature of QD solids is the ability to control the absolute energy levels by applying different ligands. This effect has been attributed to ligand-induced surface dipoles ${ }^{21}$. Such control allows the energetics within a device to be engineered by using multiple surface treatments during the QD deposition to create bilayer (or in principle, more complex) structures of QD solids. For example, Semonin et al. demonstrated increased performance in PbSe solar cells by stacking ethanedithiol- (EDT) and hydrazine-treated layers ${ }^{1}$. Other combinations using TBAI and EDT or tetramethylammoinium hydroxide have been used to enhance carrier collection resulting in improved device performance ${ }^{6,25}$. In Fig. 3B, we compare devices with only a $\mathrm{PbS}_{\mathrm{PbI} 2}$ layer to those with bilayer structures where the $\mathrm{PbS}_{\mathrm{PbI} 2}$ layer is followed by either $\mathrm{PbS}_{\mathrm{MPA}}$ or $\mathrm{PbS}_{\mathrm{NH} 4 \mathrm{SCN}}$ layers and find that the bilayer structure can greatly improve the current density-voltage $(J-V)$ characteristics of the device. Although PbS QDs treated with the inorganic SCN- ligand have been reported to be more conductive in QD films than the organic MPA ligand ${ }^{26,27}$, we find that the QD devices presented here function more efficiently with $\mathrm{PbS}_{\mathrm{PbI}} / \mathrm{PbS}_{\mathrm{MPA}}$ than $\mathrm{PbS}_{\mathrm{PbI} 2} / \mathrm{PbS}_{\mathrm{NH} 4 \mathrm{SCN}}$.

Adopting the $\mathrm{PbS}_{\mathrm{PbI} 2} / \mathrm{PbS}_{\mathrm{MPA}}$ bilayer structure, we then compare PV devices using each of the metal halides discussed. Figure $3 \mathrm{~A}$ shows a scanning electron microscopy (SEM) image of a completed $\mathrm{PbS}_{\mathrm{PbI} 2} / \mathrm{PbS}_{\mathrm{MPA}}$ device indicating highly uniform QD deposition throughout the device. The difference in contrast shown in the SEM for the $\mathrm{PbI}_{2}-v s$. MPA-capped QDs indicates that the layers remain distinct with likely different material density or perhaps conductivity. While we have optimized the device fabrication conditions for the $\mathrm{PbI}_{2}$ treatment, we note that each of the metal halides results in functioning devices and each affect the PV performance in unique ways. For example, in Fig. 3C, we show that devices fabricated using $\mathrm{CdCl}_{2}$ have an improved open circuit voltage over those fabricated from $\mathrm{PbI}_{2}$-treated QDs and reach a PCE of 5.6\%. The spectral response of a $\mathrm{CdCl}_{2}$-treated device (Fig. 3D) exhibits a 100 -nm blue shift in the wavelength of the first exciton feature that is likely due to a surface ion exchange which reduces the size of the PbS core and increases the bandgap ${ }^{28}$. Metal halide treatments can also be used 


\begin{tabular}{|c|c|c|c|c|c|c|c|c|c|c|}
\hline $\mathrm{PbS}(\mathrm{CdS})$ & $\mathrm{CdS}$ & $\mathrm{Pbl}_{2} / \mathrm{DMF}$ & MPA (10\%) & Dipcoat & $350 \mathrm{~nm}$ & 543 & 16.5 & 45.0 & 4.0 & Air \\
\hline $\mathrm{PbS}$ (CdS) & $\mathrm{TiO}_{2}$ & $\mathrm{Pbl}_{2} / \mathrm{DMF}: \mathrm{ACN} 1: 5$ & EDT (1 mM) & Dipcoat & $300 \mathrm{~nm}$ & 623 & 14.2 & 36.2 & 3.2 & Air \\
\hline $\mathrm{PbS}$ (CdS) & In: $\mathrm{ZnO}$ sol-gel & $\mathrm{Pbl}_{2} / \mathrm{DMF}: \mathrm{ACN} 1: 5$ & EDT $(1 \mathrm{mM})$ & Dipcoat & $550 \mathrm{~nm}$ & 567 & 17.4 & 42.8 & 4.2 & Air \\
\hline $\mathrm{PbS}$ (CdS) & $\mathrm{TiO}_{2}$ & MPA & N/A & Dipcoat & $400 \mathrm{~nm}$ & 542 & 6.96 & 47.1 & 1.8 & Air \\
\hline $\mathrm{PbS}$ (CdS) & $\mathrm{TiO}_{2}$ & EDT & $\mathrm{N} / \mathrm{A}$ & Dipcoat & $550 \mathrm{~nm}$ & 596 & 15.8 & 33.8 & 3.2 & Air \\
\hline $\mathrm{PbS}$ (CdS) & $\mathrm{TiO}_{2}$ & $\mathrm{Pbl}_{2} / \mathrm{DMF}$ & MPA (10\%) & Dipcoat & $350 \mathrm{~nm}$ & 584 & 25.3 & 44.8 & 6.6 & Air \\
\hline $\mathrm{PbS}(\mathrm{CdS})$ & $\mathrm{TiO}_{2}$ & $\mathrm{Pbl}_{2} / \mathrm{DMF}$ & MPA $(2 \%)$ & Spincoat & $420 \mathrm{~nm}$ & 496 & 23.0 & 43.2 & 4.9 & $\mathrm{~N}_{2}$ \\
\hline $\mathrm{PbS}$ (CdS) & $\mathrm{TiO}_{2}$ & $\mathrm{Pbl}_{2} / \mathrm{DMF}: \mathrm{ACN} 1: 5$ & $\mathrm{Na}_{2} \mathrm{~S}(10 \mathrm{mM})$ & Dipcoat & $400 \mathrm{~nm}$ & 513 & 11.9 & 19.9 & 1.2 & $\mathrm{~N}_{2}$ \\
\hline $\mathrm{PbS}$ (CdS) & $\mathrm{TiO}_{2}$ & $\mathrm{Pbl}_{2} / \mathrm{DMF}: \mathrm{ACN} 1: 5$ & $\mathrm{NH}_{4} \mathrm{SCN}(10 \mathrm{mM})$ & Dipcoat & $340 \mathrm{~nm}$ & 500 & 16.6 & 33.2 & 2.8 & $\mathrm{~N}_{2}$ \\
\hline $\mathrm{PbS}(\mathrm{CdS})$ & $\mathrm{TiO}_{2}$ & $\mathrm{Pbl}_{2}$ /DMF:ACN 1:5 & MPA $(10 \%)$ & Dipcoat & $750 \mathrm{~nm}$ & 516 & 14.1 & 48.6 & 3.5 & $\mathrm{~N}_{2}$ \\
\hline $\mathrm{PbS}$ (CdS) & $\mathrm{TiO}_{2}$ & $\mathrm{Pbl}_{2} / \mathrm{DMF}$ & MPA (10\%) - dip & Spincoat & $500 \mathrm{~nm}$ & 431 & 19.5 & 30.5 & 2.6 & $\mathrm{~N}_{2}$ \\
\hline $\mathrm{PbS}(\mathrm{CdS})$ & $\mathrm{TiO}_{2}$ & $\mathrm{Pbl}_{2} / \mathrm{DMF}$ & MPA $(10 \%)$ & Spincoat & $500 \mathrm{~nm}$ & 438 & 23.9 & 47.5 & 5.0 & $\mathrm{~N}_{2}$ \\
\hline $\mathrm{PbS}$ (CdS) & $\mathrm{TiO}_{2}$ & $\mathrm{Pbl}_{2} / \mathrm{DMF}$ & MPA (10\%) & Spincoat & $315 \mathrm{~nm}$ & 547 & 22.6 & 52.0 & 6.4 & $\mathrm{~N}_{2}$ \\
\hline $\mathrm{PbS}(\mathrm{CdS})$ & $\mathrm{TiO}_{2}$ & $\mathrm{Pbl}_{2} / \mathrm{DMF}$ & MPA (10\%) & Spincoat & $470 \mathrm{~nm}$ & 547 & 22.7 & 53.0 & 6.6 & $\mathrm{~N}_{2}$ \\
\hline $\mathrm{PbS}$ (CdS) & $\mathrm{TiO}_{2}$ & $\mathrm{Pbl}_{2} / \mathrm{DMF}$ & MPA (10\%) & Spincoat & $500 \mathrm{~nm}$ & 559 & 25.5 & 51.0 & 7.3 & $\mathrm{~N}_{2}$ \\
\hline $\mathrm{PbS}(\mathrm{CdS})$ & $\mathrm{TiO}_{2}$ & $\mathrm{Pbl}_{2} / \mathrm{DMF}$ & MPA (10\%) & Spincoat & $585 \mathrm{~nm}$ & 554 & 25.0 & 50.0 & 7.0 & $\mathrm{~N}_{2}$ \\
\hline $\mathrm{PbS}$ (CdS) & $\mathrm{TiO}_{2}$ & $\mathrm{Pbl}_{2} / \mathrm{DMF}$ & MPA (10\%) & Spincoat & $740 \mathrm{~nm}$ & 519 & 22.4 & 41.0 & 4.7 & $\mathrm{~N}_{2}$ \\
\hline $\mathrm{PbS}(\mathrm{CdS})$ & $\mathrm{TiO}_{2}$ & $\mathrm{PbCl}_{2} / \mathrm{DMF}$ & MPA (10\%) & Spincoat & $580 \mathrm{~nm}$ & 354 & 4.66 & 41.0 & 0.7 & $\mathrm{~N}_{2}$ \\
\hline $\mathrm{PbS}$ (CdS) & $\mathrm{TiO}_{2}$ & $\mathrm{Cdl}_{2} / \mathrm{DMF}$ & MPA (10\%) & Spincoat & $580 \mathrm{~nm}$ & 421 & 21.2 & 42.1 & 3.8 & $\mathrm{~N}_{2}$ \\
\hline $\mathrm{PbS}$ (CdS) & $\mathrm{TiO}_{2}$ & $\mathrm{CdCl}_{2} / \mathrm{DMF}$ & MPA (10\%) & Spincoat & $580 \mathrm{~nm}$ & 620 & 19.9 & 45.1 & 5.6 & $\mathrm{~N}_{2}$ \\
\hline
\end{tabular}

to fabricate PbSe QDSCs under ambient conditions (PbSe is generally more prone to oxidation than $\mathrm{PbS}$ ). The $J-V$ characteristics of a $1.3 \mathrm{eV}$ bandgap PbSe QDs device are shown in Fig. 3E with the
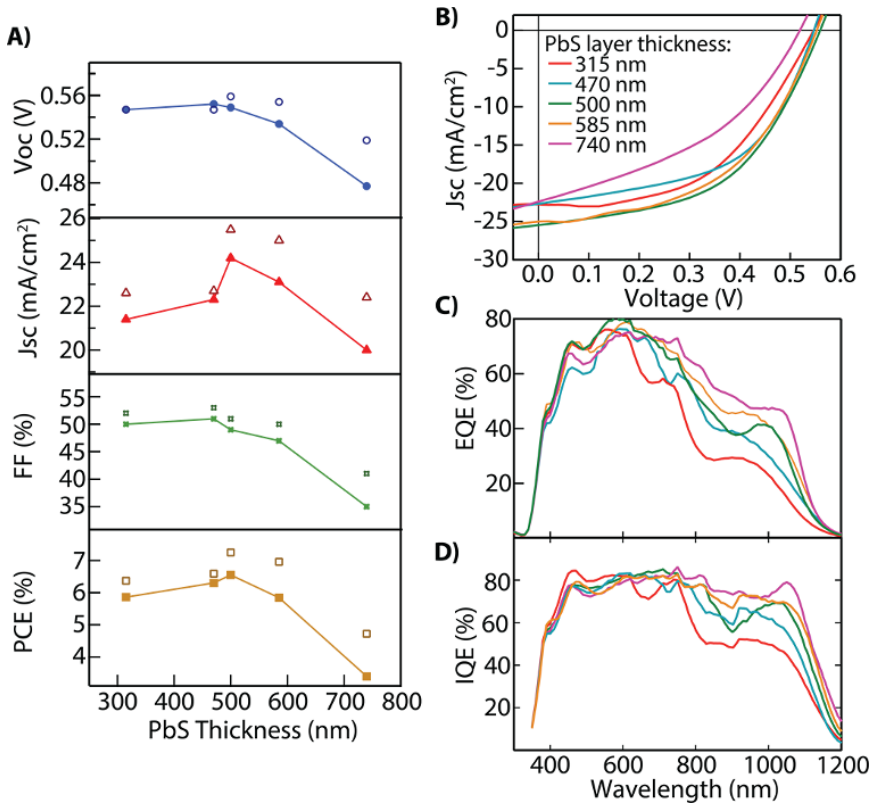

Figure $4 \mid$ A) $\mathrm{V}_{\mathrm{OC}}, \mathrm{J}_{\mathrm{SC}}, \mathrm{FF}$, and PCE plotted as a function of device thickness for spincoated $\mathrm{PbI}_{2}$-treated devices. Solid symbols represent the average of 6 devices and hollow symbols are the best devices. B) $J$ - $V$ curves of cells shown in panel A with the best cell reaching a PCE of $7.25 \%$ with $500 \mathrm{~nm}$ thickness of the QD layer. C) EQE response of cells showing improved response of longer wavelength light as the cell absorbs more light. D) Internal quantum efficiency (IQE) determined by dividing the EQE by the absorption. The color coding is consistent in panels B-D and annotated in the legend of panel B. inset showing the external quantum efficiency (EQE) of the device with $>70 \%$ response throughout most of the visible spectrum.

We test the thickness dependence of the PbS absorber layer by producing devices composed of $4,6,7,8$, and 10 sequential spin coating steps. After each spin, the film is treated by soaking in $10 \mathrm{mM} \mathrm{PbI}_{2}$ in DMF for 3 minutes. The last two coatings were treated by $10 \% \mathrm{MPA}$ in methanol rather than $\mathrm{PbI}_{2}$. In Fig. $4 \mathrm{~A}$, we plot the open-circuit voltage $\left(\mathrm{V}_{\mathrm{OC}}\right)$, short-circuit current $\left(\mathrm{J}_{\mathrm{SC}}\right)$, fill factor (FF), and PCE as a function of the total QD layer thickness. The solid symbols represent the average of 6 devices and the hollow symbols represent the champion device for each film thickness. Current-voltage characteristics of the devices are shown in Fig. 4B with the best device reaching a PCE of $7.25 \%$ which corresponds to a thickness of $500 \mathrm{~nm}$. Figure $4 \mathrm{C}$ shows the EQE response of the devices as a function of thickness and indicates a general trend of increasing spectral response for lower energy photons (i.e. photons with wavelength between 600 and $1200 \mathrm{~nm}$ ). We also determined that the internal quantum efficiency (IQE) increases in this same manner with the thickest cell showing a flat response of $80-85 \%$ (Fig. 4D). Ideally, the IQE should be independent of the cell thickness unless there is high carrier recombination at the back interface. For the device with a PbS QD thickness of $740 \mathrm{~nm}$, the IQE is roughly $80 \%$ for all photons absorbed in the QD layer (i.e. photon energy above the bandgap of the PbS QDs and below the absorption of the glass/ITO substrate). Electron transport is sufficient to extract $80 \%$ of carriers generated in the device, indicated by the IQE and flat spectrum, despite being significantly thicker than the highest efficiency reported $\mathrm{PbS}$ QDSC ${ }^{6}$. The $\mathrm{PbI}_{2}$ treatment described here is, therefore, very promising for improving the overall efficiency of QDSCs as the $\mathrm{J}_{\mathrm{SC}}$ only begins to drop as the film thickness approaches $740 \mathrm{~nm}$.

To conclude, we present metal halide treated films of $\mathrm{PbE}$ yielding high efficiency devices. This inorganic ligand treatment allows for relatively thick films $(\sim 600 \mathrm{~nm})$ to be incorporated into devices while still maintaining good transport (i.e. high current) in the 
device. The XPS results highlight the control over the PbS QD absorber layer by choice of ligand. We have shown with XPS that different chemical treatments affect the QD surface, and subsequently, how these surface treatments directly control the energy levels of the QD absorber layer. Additionally, XPS and FTIR analysis confirmed that the metal halide exchange lessens the residual organic elements in the film. Furthermore, using PbS QDs as the low bandgap cell in tandem configurations where better collection of the near infrared photons is needed is now more feasible as collection efficiency throughout nearly the entire spectrum exceeds $50 \%$ with an absorber thickness $>700 \mathrm{~nm}$.

\section{Methods}

The QDs were synthesized following a previously published procedure ${ }^{4}$. For PbSe, CdSe was first synthesized following a modified version of the procedure published by $\mathrm{Pu}$ et al. ${ }^{29}$ to obtain $\sim 5 \mathrm{~nm}$, monodisperse CdSe. The CdSe was then chemically converted to PbSe through a cation exchange reaction by mixing $0.834 \mathrm{~g} \mathrm{PbCl}_{2}$ with $10 \mathrm{~mL}$ oleylamine (OLA), degassing, and heating to $140^{\circ} \mathrm{C}$ for $30 \mathrm{~min}$. The mixture was then heated to $190^{\circ} \mathrm{C}$ and $2 \mathrm{~mL}$ of CdSe $(100 \mathrm{mg} / \mathrm{mL}$, in ODE) is injected. The reaction was left at $180^{\circ} \mathrm{C}$ for 30 seconds then quenched with a water bath. As the reaction cools, $10 \mathrm{~mL}$ hexane and $8 \mathrm{~mL} \mathrm{OA}$ are injected at $70^{\circ} \mathrm{C}$ and $30^{\circ} \mathrm{C}$, respectively. The reaction was allowed to cool and the QDs were washed by precipitationredispersion with ethanol and hexane. The final dispersion was centrifuged to remove any excess chloride salts and filtered through a $0.2 \mu \mathrm{m}$ Nylon filter.

$\mathrm{PbS}$ was synthesized by the cation exchange of $\mathrm{CdS}$. CdS was synthesized following the procedure published by Zhang et al. ${ }^{30}$. The cation exchange follows that of the CdSe, except the precursors are cooled to $90^{\circ} \mathrm{C}$ before the injection of CdS $(150 \mathrm{mg} / \mathrm{mL}$ in toluene) and the reaction runs for 60 seconds. The product was washed and filtered in the same way as described above.

The FTIR absorbance measurements were taken on a Thermo-Nicolet 6700 FT-IR spectrometer in transmission mode with a resolution of $4 \mathrm{~cm}^{-1}$. Clean Si plates were used for background measurements, and films of OA-capped QDs were drop cast onto the Si plates for the oleate-capped measurements. The samples were then submerged in $10 \mathrm{mM}$ metal halide in DMF solutions for 2 hours and rinsed with acetonitrile. These metal halide treated samples were then measured, and spectra with sloping baselines were baseline-corrected.

The XPS measurements were performed on a Physical Electronics, Inc. 5600 ESCA instrument, which has been discussed in detail previously $y^{31}$. Briefly, the radiation is produced by a monochromatic $\mathrm{Al}(\mathrm{K} \alpha)$ source centered at $1486.6 \mathrm{eV}$. The VB spectra were taken with a step size of $0.05 \mathrm{eV}$ and a pass energy of $5.85 \mathrm{eV}$. The electron binding energy scale was calibrated using the Fermi edge of cleaned metallic substrates ( $\mathrm{Au}, \mathrm{Mo}, \mathrm{Cu}$, and/or $\mathrm{Ag}$ ), giving the spectra an uncertainty of $\pm 0.05 \mathrm{eV}$. We verify that charging during the photoemission experiments is insignificant by measuring the X-ray power dependence of various spectral features (core levels, VBMs, and/or secondary electron cutoffs). We find the VB onset by determining the intersection between the baseline and a linear fit to the main VB feature ${ }^{32}$.

Solar cell fabrication consisted of dip coating or spin-coating on patterned ITO-coated glass slides from Thin Film Devices where we first deposited a $\mathrm{TiO}_{2}$ layer with a sol-gel method. $\mathrm{TiO}_{2}$ sol-gel was prepared in air by mixing $5 \mathrm{~mL}$ anhydrous ethanol, 2 drops hydrochloric acid, and $125 \mu \mathrm{L}$ DI water. This mixture was stirred while $375 \mu \mathrm{L}$ titanium ethoxide is added drop-wise to ensure that no precipitates form. This yielded a clear liquid that was stirred for 48 hours with the headspace of the vial filled with nitrogen. It was then stored in a freezer until needed. The ITO/glass substrates were cleaned vigorously with ethanol and UV-ozone treated before depositing $\mathrm{TiO}_{2}$. Within 10 min of UV-ozone treatment, $70 \mu \mathrm{L} \mathrm{TiO}_{2}$ sol-gel was spun at $1400 \mathrm{RPM}$ for $30 \mathrm{sec}$. The $\mathrm{TiO}_{2}$ is wiped off the ITO contact pads using ethanol and the films are dried at $115^{\circ} \mathrm{C}$ then annealed at $450^{\circ} \mathrm{C}$ for $30 \mathrm{~min}$. The films are stored in air and sit in air for at least 1 day before use. For dip coating, immersing the substrates into a $\sim 15 \mathrm{mg} / \mathrm{mL}$ solution of QDs in hexane and smoothly removing them leaves a thin film of QDs as discussed previously ${ }^{17}$. Dipping this film into the $10 \mathrm{mM}$ metal halide/DMF solution for 30-60 seconds renders the QD layer insoluble in hexane and allows for thick films to be built up layer-by-layer (where the term "layer" does not imply a monolayer of QDs, but rather one coating of QDs). A post-ligand treatment with neat acetonitrile $(\mathrm{ACN})$ was necessary to remove the DMF because the residual DMF does not dry rapidly. It should be noted that the metal halides discussed here are not appreciably soluble in $\mathrm{ACN}$ making $\mathrm{ACN}$ a poor choice of solvent for the ligand exchange. A mixture of 20 vol.\% DMF/ACN solvated the $\mathrm{PbI}_{2}$ and devices made in this fashion performed nearly as well as those with $\mathrm{PbI}_{2}$ in $\mathrm{DMF}$ for the ligand treatment solvent (Table 2). Typical dip coated devices used 10-15 layers of $\mathrm{PbI}_{2}$-treated QDs followed by 3-4 layers treated with 10\% MPA in methanol (MeOH) or alternatively a $10 \mathrm{mM}$ solution in $\mathrm{MeOH}$ was used for the $\mathrm{NH}_{4} \mathrm{SCN}$ treatment. Spin coated devices used a variable number of layers for the $\mathrm{PbI}_{2}$-treatment as discussed in the manuscript with 2 layers of MPA-capped QDs in each case. The QDs were dispersed in octane at a concentration of $40 \mathrm{mg} / \mathrm{mL}$ and spun at $1000 \mathrm{rpm}$ for $45 \mathrm{~s}$ before being immersed in $10 \mathrm{mM}$ metal halide solution for 3 minutes and rinsed with $\mathrm{ACN}$. The last 2 cycles of QDs were treated with $10 \% \mathrm{MPA}$ in $\mathrm{MeOH}$ by dipping the device into a MPA/MeOH solution, rinsing twice with $\mathrm{MeOH}$ and drying with nitrogen. All devices presented here were fabricated at room temperature $\left(\sim 23.9-26.7^{\circ} \mathrm{C}\right)$ and relative humidity that fluctuates between $16-20 \%$.

A $\mathrm{MoO}_{\mathrm{x}} / \mathrm{Al}$ back contact was then thermally evaporated as discussed by Gao et al. ${ }^{3 .}$.

Device testing was carried out using Newport solar simulators adjusted by measuring a calibrated Si photodiode reference to match the AM1.5 spectrum. Some devices were tested in glovebox atmosphere while others were tested in air; details annotated in Table 2. Device area is $0.11 \mathrm{~cm}^{2}$ but an aperture of $0.059 \mathrm{~cm}^{2}$ was used to define the active illuminated area. Spectral response measurements were performed on an Oriel IQE-200 system.

1. Semonin, O. E. et al. Peak external photocurrent quantum efficiency exceeding $100 \%$ via MEG in a quantum dot solar cell. Science 334, 1530-1533 (2011).

2. Semonin, O. E., Luther, J. M. \& Beard, M. C. Quantum dots for next-generation photovoltaics. Mater. Today 15, 508-515 (2012).

3. Zhang, J., Gao, J., Miller, E. M., Luther, J. M. \& Beard, M. C. Diffusion-controlled synthesis of $\mathrm{PbS}$ and $\mathrm{PbSe}$ quantum dots with in situ halide passivation for quantum dot solar cells. ACS Nano 8, 614-622 (2013).

4. Zhang, J. et al. PbSe quantum dot solar cells with more than $6 \%$ efficiency fabricated in ambient atmosphere. Nano Lett. 14, 6010-6015 (2014).

5. Kramer, I. J. \& Sargent, E. H. The architecture of colloidal quantum dot solar cells: Materials to devices. Chem. Rev. 114, 863-882 (2013).

6. Chuang, C.-H. M., Brown, P. R., Bulović, V. \& Bawendi, M. G. Improved performance and stability in quantum dot solar cells through band alignment engineering. Nat. Mater. 13, 796-801 (2014).

7. Tang, J. et al. Colloidal-quantum-dot photovoltaics using atomic-ligand passivation. Nat. Mater. 10, 765-771 (2011).

8. Bae, W. K. et al. Highly effective surface passivation of PbSe quantum dots through reaction with molecular chlorine. J. Am. Chem. Soc. 134, 20160-20168 (2012).

9. Zhitomirsky, D. et al. Engineering colloidal quantum dot solids within and beyond the mobility-invariant regime. Nat. Commun. 5, 3803 (2014).

10. Ip, A. H. et al. Hybrid passivated colloidal quantum dot solids. Nat. Nanotechnol. 7, 577-582 (2012)

11. Crisp, R. W. et al. Nanocrystal grain growth and device architectures for high-efficiency CdTe ink-based photovoltaics. ACS Nano 8, 9063-9072 (2014).

12. Ning, Z., Dong, H., Zhang, Q., Voznyy, O. \& Sargent, E. H. Solar cells based on inks of n-type colloidal quantum dots. ACS Nano 8, 10321-10327 (2014).

13. Niu, G. et al. Inorganic halogen ligands in quantum dots: $\mathrm{I}-, \mathrm{Br}-$, $\mathrm{Cl}-$ and film fabrication through electrophoretic deposition. PCCP. 15, 19595-19600 (2013).

14. Dirin, D. N. et al. Lead halide perovskites and other metal halide complexes as inorganic capping ligands for colloidal nanocrystals. J. Am. Chem. Soc. 136, 6550-6553 (2014).

15. Zhang, H., Jang, J., Liu, W. \& Talapin, D. V. Colloidal nanocrystals with inorganic halide, pseudohalide, and halometallate ligands. ACS Nano 8, 7359-7369 (2014).

16. Baumgardner, W. J., Whitham, K. \& Hanrath, T. Confined-but-connected quantum solids via controlled ligand displacement. Nano Lett. 13, 3225-3231 (2013).

17. Luther, J. M. et al. Structural, optical and electrical properties of self-assembled films of PbSe nanocrystals treated with 1,2-ethanedithiol. ACS Nano 2, 271-280 (2008).

18. Luther, J. M. \& Pietryga, J. M. Stoichiometry control in quantum dots: A viable analog to impurity doping of bulk materials. ACS Nano 7, 1845-1849 (2013).

19. Oh, S. J. et al. Designing high-performance PbS and PbSe nanocrystal electronic devices through stepwise, post-synthesis, colloidal atomic layer deposition. Nano Lett. 14, 1559-1566 (2014).

20. Oh, S. J. et al. Stoichiometric control of lead chalcogenide nanocrystal solids to enhance their electronic and optoelectronic device performance. ACS Nano 7, 2413-2421 (2013).

21. Brown, P. R. et al. Energy level modification in lead sulfide quantum dot thin films through ligand exchange. ACS Nano 8, 5863-5872 (2014).

22. Choi, H., Ko, J.-H., Kim, Y.-H. \& Jeong, S. Steric-hindrance-driven shape transition in PbS quantum dots: Understanding size-dependent stability. J. Am. Chem. Soc. 135, 5278-5281 (2013).

23. Jasieniak, J., Califano, M. \& Watkins, S. E. Size-dependent valence and conduction band-edge energies of semiconductor nanocrystals. ACS Nano 5, 5888-5902 (2011).

24. Munro, A. M., Zacher, B., Graham, A. \& Armstrong, N. R. Photoemission spectroscopy of tethered CdSe nanocrystals: Shifts in ionization potential and local vacuum level as a function of nanocrystal capping ligand. ACS Appl. Mater. Interfaces 2, 863-869 (2010).

25. Zhitomirsky, D. et al. N-type colloidal-quantum-dot solids for photovoltaics. Adv. Mater. 24, 6181-6185 (2012).

26. Fafarman, A. T. et al. Thiocyanate-capped nanocrystal colloids: Vibrational reporter of surface chemistry and solution-based route to enhanced coupling in nanocrystal solids. J. Am. Chem. Soc. 133, 15753-15761 (2011).

27. Jeong, K. S. et al. Enhanced mobility-lifetime products in PbS colloidal quantum dot photovoltaics. ACS Nano 6, 89-99 (2011).

28. Pietryga, J. M. et al. Utilizing the lability of lead selenide to produce heterostructured nanocrystals with bright, stable infrared emission. J. Am. Chem Soc. 130, 4879-4885 (2008).

29. Pu, C. et al. Highly reactive, flexible yet green Se precursor for metal selenide nanocrystals: Se-octadecene suspension (Se-Sus). Nano Res. 6, 652-670 (2013). 
30. Zhang, H., Hyun, B.-R., Wise, F. W. \& Robinson, R. D. A generic method for rational scalable synthesis of monodisperse metal sulfide nanocrystals. Nano Lett. 12, 5856-5860 (2012).

31. Perkins, C. L. \& Hasoon, F. S. Surfactant-assisted growth of CdS thin films for photovoltaic applications. J. Vac. Sci. Technol. A. 24, 497-504 (2006).

32. Kraut, E. A., Grant, R. W., Waldrop, J. R. \& Kowalczyk, S. P. Semiconductor core-level to valence-band maximum binding-energy differences: Precise determination by x-ray photoelectron spectroscopy. Phys. Rev. B. 28, 1965-1977 (1983).

33. Gao, J. et al. N-type transition metal oxide as a hole extraction layer in $\mathrm{PbS}$ quantum dot solar cells. Nano Lett. 11, 3263-3266 (2011).

\section{Acknowledgments}

The development of the quantum dot synthesis and characterization in this work are supported by the U.S. Department of Energy Office of Science, Office of Basic Energy Sciences Energy Frontier Research Centers program within the Center for Advanced Solar Photophysics through contract number DE-AC36-08GO28308. The device work presented here is supported by the U.S. Department of Energy (DOE) SunShot program under Award No. DE-EE0005312. EMM acknowledges funding through the NREL Directors Fellowship program.

\section{Author contributions}

R.C. developed the $\mathrm{PbI}_{2}$ ligand exchange, synthesized $\mathrm{PbS} \mathrm{QDs}$, fabricated and characterized PbS devices and materials. D.K. performed and analyzed the FTIR experiments. A.M. synthesized PbSe QDs, fabricated and measured PbSe devices. E.M. performed and analyzed photoelectron experiments. J.Z. optimized the QD synthesis. M.B. and J.L. conceived the experiments, analyzed the results and oversaw the project. All authors aided in preparing and editing the manuscript.

\section{Additional information}

Competing financial interests: The authors declare no competing financial interests.

How to cite this article: Crisp, R.W. et al. Metal Halide Solid-State Surface Treatment for High Efficiency PbS and PbSe QD Solar Cells. Sci. Rep. 5, 9945; DOI:10.1038/srep09945 (2015).

This work is licensed under a Creative Commons Attribution 4.0 International License. The images or other third party material in this article are included in the article's Creative Commons license, unless indicated otherwise in the credit line; if the material is not included under the Creative Commons license, users will need to obtain permission from the license holder in order to reproduce the material. To view a copy of this license, visit http://creativecommons.org/licenses/by/4.0/ 